\title{
Telomere Attrition Occurs during Ex Vivo Expansion of Human Dental Pulp Stem Cells
}

\author{
Jaroslav Mokry, ${ }^{1}$ Tomas Soukup, ${ }^{1}$ Stanislav Micuda, ${ }^{2}$ Jana Karbanova, ${ }^{1}$ \\ Benjamin Visek, ${ }^{1}$ Eva Brcakova, ${ }^{2}$ Jakub Suchanek, ${ }^{3}$ Jan Bouchal, ${ }^{4}$ Doris Vokurkova, ${ }^{5}$ \\ and Romana Ivancakova ${ }^{3}$ \\ ${ }^{1}$ Department of Histology and Embryology, Faculty of Medicine in Hradec Kralove, Charles University in Prague, Simkova 870, \\ 50038 Hradec Kralove, Czech Republic \\ ${ }^{2}$ Department of Pharmacology, Faculty of Medicine in Hradec Kralove, Charles University in Prague, Simkova 870, \\ 50038 Hradec Kralove, Czech Republic \\ ${ }^{3}$ Department of Dentistry, Faculty of Medicine in Hradec Kralove, Charles University in Prague, Sokolska 581, \\ 50005 Hradec Kralove, Czech Republic \\ ${ }^{4}$ Laboratory of Molecular Pathology, Faculty of Medicine, Palacký University, Hnevotinska 3, 77515 Olomouc, Czech Republic \\ ${ }^{5}$ Department of Clinical Immunology and Allergology, Faculty of Medicine in Hradec Kralove, Charles University in Prague, \\ Sokolska 581, 50005 Hradec Kralove, Czech Republic
}

Correspondence should be addressed to Jaroslav Mokry, mokry@lfhk.cuni.cz

Received 4 May 2010; Revised 5 August 2010; Accepted 31 August 2010

Academic Editor: Manoor Prakash Hande

Copyright ( 2010 Jaroslav Mokry et al. This is an open access article distributed under the Creative Commons Attribution License, which permits unrestricted use, distribution, and reproduction in any medium, provided the original work is properly cited.

We provide a detailed characteristic of stem cells isolated and expanded from the human dental pulp. Dental pulp stem cells express mesenchymal cell markers STRO-1, vimentin, CD29, CD44, CD73, CD90, CD166, and stem cell markers Sox2, nestin, and nucleostemin. They are multipotent as shown by their osteogenic and chondrogenic potential. We measured relative telomere length in 11 dental pulp stem cell lines at different passages by quantitative real-time PCR. Despite their large proliferative capacity, stable viability, phenotype, and genotype over prolonged cultivation, human dental pulp stem cells suffer from progressive telomere shortening over time they replicate in vitro. Relative telomere length $(\mathrm{T} / \mathrm{S})$ was inversely correlated with cumulative doubling time. Our findings indicate that excessive ex vivo expansion of adult stem cells should be reduced at minimum to avoid detrimental effects on telomere maintenance and measurement of telomere length should become a standard when certificating the status and replicative age of stem cells prior therapeutic applications.

\section{Introduction}

Within adult multicellular organisms populations of stem cells are responsible for tissue maintenance and regeneration. Since these primitive cells are endowed with unique biological properties like unlimited self-renewal, extensive proliferative capacity, and broad differentiation potential, they represent a promising tool for cell replacement strategies in treatment of degenerating and ageing tissues. Stem cells have been identified in most tissues of both developing (e.g., [13]) and adult organisms (e.g., [4-6]). The dental pulp is no exception. The dental pulp is well-delineated compartment with connective tissue that structurally resembles primitive connective tissues. Few studies gave evidence that this tissue contains a special population of adult stem cells [7-9]. These studies characterized dental pulp stem cells (DPSCs) cultured under different in vitro conditions and reported some similarity to bone marrow mesenchymal stem cells, for example, in expression of mesenchymal markers as well as differences in some biological properties such as distinct growth kinetics and capacity to restore dental structures.

In order to perform their vital functions until old age, stem cells are endowed with diverse mechanisms contributing to stem cells resistance and longevity. For example, asymmetric division [10] prevents stem cell exhaustion. In tissues, stem cells are placed in a protective microenvironment 
(niche). Moreover, stem cells have lower reactive oxygen species levels than somatic cells [11] and also have multiple specific molecular mechanisms [12] including proteins of detoxifier system, which provide additional protection against noxious stimuli. All these and other factors prolong lifespan of stem cells.

In eukaryotes, the chronological cell ageing is checked through telomere shortening of their chromosomes. The ends of linear chromosomes are capped with a series of tandem repeat noncoding TTAGGG sequences that are protected within a higher order nucleoprotein complex. These telomeres protect chromosome from end-to-end fusions, recombination, and degeneration (reviewed in [13]). However, with each cell division, the most distal telomere repeats are lost as a result of end-replication problem. Uncompensated, repeated cell divisions lead to a critical shortening of telomeres which in turn triggers cellular senescence and proliferation arrest [14]. In stem cells, a specific ribonucleoprotein enzyme, telomerase, compensates for telomere shortening (e.g., [15-17]). This enzymatic activity has been also reported in DPSCs where telomerase levels were higher than in mesenchymal stem cells [18] which make DPSCs suitable candidates for ex vivo expansion. A big advantage of tissue-specific stem cells over embryonic stem (ES) cells is their histocompatibility with patient's tissues. However, for regenerative transplantation therapies vast numbers of stem cells are required. Stem cells are rare cells found in the tissues and as a result, isolation of tissuespecific stem cells from a single dental pulp yields 10 to 110 initial cells that adhere and multiplicate [8]. An exponential increase in stem cell numbers can be reached in relatively short time when these cells are expanded in vitro with mitogenic growth factors.

In this paper, we extended DPSC characteristics grown in cultivation medium with a reduced level of serum. Growth kinetics characterized by population doublings confirmed a large proliferative capacity of DPSC lines. Immunophenotypisation of DPSCs carried out with flow cytometry and immunocytochemistry revealed expression of stem cellspecific markers. Cultivation of DPSCs in differentiation assays gave evidence of their multilineage potential. Finally, we analyzed relative telomere length in DPSCs at different passages with quantitative real-time PCR and obtained valuable information on changes that were associated with long-term cultivation. Although DPSCs remained stable in their viability, phenotype, and genotype over-prolonged cultivation, progressive telomere shortening detected by us indicated that adult tissue-specific stem cells might be at risk of detrimental effects caused by excessive ex vivo expansion.

\section{Material and Methods}

2.1. DPSC Isolation and Cultivation. Impacted third molars were obtained from healthy donors (impacted third molars: 18-27 years of age, 5 females and 5 males; exfoliated incisor: 8 years, 1 female) at the Department of Dentistry under approved guidelines of the Ethical Committee of the Faculty
Hospital in Hradec Králové. Patients or their parents signed an informed consent statement. The isolation and culture of DPSCs were performed according to protocol described Suchanek et al. [19]. Briefly, after the dental pulp was retrieved, it was dissociated enzymatically with collagenase type I $3 \mathrm{mg} / \mathrm{mL}$ (Sevapharma, Czech Republic) and dispase $4 \mathrm{mg} / \mathrm{mL}$ (Gibco, UK). The harvested cells were splitted into two dishes: cells in the first dish were propagated to generate maximum cell numbers; these cells underwent standard passaging procedure including cell counting. The second dish was used for measurement of CFU-F numbers in the primary culture (see below). The cells were cultivated under humidified $5 \% \mathrm{CO}_{2}$ atmosphere at $37^{\circ} \mathrm{C}$ in basic expansion medium consisting of alpha-MEM (Gibco, UK) supplemented with $2 \%$ FCS (PAA, USA), $10 \mathrm{ng} / \mathrm{mL}$ EGF (PeproTech, USA), $10 \mathrm{ng} / \mathrm{mL}$ PDGF (PeproTech, USA), L-ascorbic acid (Sigma, USA), 2\% glutamine (Gibco, UK), penicillin/streptomycin (Gibco, UK), gentamycin (Gibco, UK), dexamethasone (Sigma, USA), and $10 \mu \mathrm{L} / \mathrm{mL}$ ITS (Sigma). After formation of small colonies, the cells were dissociated with trypsin-EDTA (Gibco, UK) and then reseeded. Cells were passaged each time after reaching $70 \%$ confluence. Cell viability and number of population doublings were examined using Vi-Cell analyzer and Z2-Counter (both from Beckman Coulter, USA). For CFU-F assays, culture medium was aspirated after 5 days of cultivation, the dish was washed with phosphate-buffer saline (PBS) and adhering cells were fixed with 3.7\% formaldehyde in PBS. CFUs were visualized with May-Grünwald, Giemsa-Romanowsky staining. After washing, all colonies in a dish were counted. Karyotypisation was carried out in passage p2, p5, and p10 in all cell lines. The cells were subjected to a 4-hour Demecolcemid (Sigma, USA) incubation followed by trypsin-EDTA detachment and lysis with hypotonic $\mathrm{KCl}$ and fixation in acid/alcohol. Cells in metaphasis were analyzed after GTG banding using software Ikaros v5.0 (MetaSystems, USA).

2.2. Flow Cytometry. For flow cytometric analysis, cells were detached and stained sequentially with primary antibodies conjugated with fluorescein or phycoerythrin until analysis with Cell Lab Quanta (Beckman Coulter, USA). DNA analysis was performed by DNA Prep kit (Beckman Coulter, USA) based on propidium iodide staining, according to manufacturer's instructions. Percentage of positive cells was determined as a percentage of cells with higher fluorescence intensity than the upper $0.5 \%$ isotype immunoglobulin control. Classification criteria: $<10 \%$ no expression, $10 \%-$ $40 \%$ low expression, $40 \%-70 \%$ moderate expression, and $>70 \%$ high expression.

DPSCs were analyzed for CD29 (TS2/16, BioLegend, USA), CD31 (MBC 78.2, Invitrogen, USA), CD34 (581 (Class III), Invitrogen, USA), CD44 (MEM 85, Invitrogen, USA), CD45 (HI30, Invitrogen, USA), CD71 (T56/14, Invitrogen, USA), CD73 (AD2, BD Biosciences Pharmingen, Belgium), CD90 (F15-42-1-5, Beckman Coulter, USA), CD105 (SN6, Invitrogen, USA), CD106 (STA, BioLegend, USA), CD146 (TEA1/34, Beckman Coulter, USA), CD166 (3A6, Beckman Coulter, USA), and HLA I (Tü149, Invitrogen, USA). 
2.3. Immunofluorescence. For detection of cytoskeletal proteins, cells were fixed with methanol/acetone at $-20^{\circ} \mathrm{C}$ for 6 minutes. For detection of other intracellular molecules, cells were fixed with $4 \%$ paraformaldehyde at $20^{\circ} \mathrm{C}$ for 10 minutes and permeabilized with $0.1 \%$ Triton X-100 for 10 minutes. For identification of cell surface antigens, cells were fixed with $4 \%$ paraformaldehyde at $20^{\circ} \mathrm{C}$ for 10 minutes. Blocking and diluent solution consisted of PBS, 5\% serum (Sigma) from the same species as was the primary antibody for 30 minutes. The samples were then incubated with primary antibody for 90 minutes. Primary antibodies used in this study were specific for the following antigens: CD90 (clone F-15-42-1, 1:100, Acris Antibodies GmbH, Germany), CD166 (3A6, 1:50, BD Biosciences, USA), CXCR4 (rabbit polyclonal, 1:100, Acris), nucleostemin (goat polyclonal, 1:10, R\&D Systems, USA), nestin (10C2, 1:200, Chemicon, USA), Sox-2 (rabbit polyclonal, $1: 100$, Chemicon), STRO-1 (STRO-1, $1: 4$, DSHB, USA), and vimentin (V9, 1:40, Sigma). After washing with PBS, the antigen-binding sites were visualized with secondary antibody conjugated to fluorochromes. We used incubations with goat anti-rabbit $\operatorname{IgG}$ coupled to Alexa 488 (1:300, Invitrogen) or goat anti-mouse IgG coupled to $\mathrm{Cy} 3(1: 300$, Jackson Immunoresearch, USA) for 30 minutes. As negative controls, matching mouse isotype controls were used or cells were stained with omission of a primary antibody. As controls, isotype $\operatorname{IgG} 1 \kappa$ and $\operatorname{IgM} \kappa(\mathrm{Abcam}, \mathrm{UK})$ were used. Cell nuclei were counterstained with DAPI (4' -6-diamidino2-phenylindole) (Sigma) for 5 minutes. Coverslips were mounted in Mowiol or polyvinyl/alcohol/glycerol with 1,4diazabicyclo-[2.2.2]-octane (DABCO) as antifading agent. Samples were examined with BX51 microscope (Olympus) equipped with DP71 digital camera. The images were prepared using Adobe Photoshop software.

2.4. Differentiation Assays. Differentiation potential of DPSCs was examined in the passage $\mathrm{p} 2$ and $\mathrm{p} 5$. Osteogenesis was triggered by spontaneous aggregation of DPSCs seeded in osteogenic medium containing alpha-MEM, $0.5 \mathrm{mM}$ ascorbic acid (Sigma), $10 \mathrm{mM} \beta$-glycerolphosphate (Sigma) and $0.1 \mu \mathrm{M}$ of dexamethasone (Sigma), and $10 \%$ FCS either in monolayer or in cell pellets. Multilayered osteogenic nodules and micromass pellets were harvested after 3-4 weeks.

Chondrogenesis was initiated in culture by means of micromass techniques. Passaged DPSCs were trypsinized and resuspended in serum-free basal medium supplemented with $50 \mathrm{ng} / \mathrm{mL}$ TGF- $\beta 1$ (Stem Cell Technologies, Canada) and cultured in 4-mL polypropylene conical tubes (Sarstedt, Germany) for 2 weeks. The chondrogenic medium was replenished twice a week.

Adipogenic differentiation was induced in a monolayer when DPSCs reached 70\% confluence either with medium containing 10\% horse serum (PAA, USA) or with adipogenic induction medium ( $\alpha$-MEM) (Invitrogen) supplemented with $10 \%$ FCS (PAA), $1 \mu \mathrm{M}$ dexamethasone (Sigma), $0.2 \mathrm{mM}$ indomethacin (Sigma), $0.01 \mathrm{mg} / \mathrm{mL}$ insulin (Sigma), and $0.5 \mathrm{mM}$ 3-isobutyl-1-methyl-xanthine (Sigma). Cultivation medium was exchanged twice a week. After four weeks, cultures were fixed with $70 \%$ ethanol and stained with oil red.

2.5. Histology. 3D micromass cultures or osteogenic bodies harvested from cultures were fixed with $10 \%$ formalin, embedded in paraffin, and cut in $7 \mu \mathrm{m}$ sections. After deparaffinisation, the sections were stained with alcian blue (for 30 minutes in $1 \%$ alcian blue solution in 3\% acetic acid), trichrome staining (modified according to Masson or Ladewig), or processed for anti-osteonectin immunohistochemistry. Prior immunostaining, the sections were exposed to microwaves $(700 \mathrm{~W})$ in sodium citrate solution $(2 \times 5$ minutes $)$ for antigen retrieval. After a thorough washing with distilled water, endogenous peroxidase activity was quenched in $3 \%$ hydrogen peroxide $(3 \times 10$ minutes $)$. Following incubation with $5 \%$ normal goat serum in PBS for 20 minutes, the sections were treated with anti-osteonectin antibody (15G12, 1:40, Novocastra, UK) at $4^{\circ} \mathrm{C}$ overnight. After washing, sections were incubated with anti-mouse EnVision peroxidase kit (Dako, Denmark) according to the manufacturer's protocol. Antigen was visualized with DAB (3,3'-diaminobenzidine tetrahydrochloride, Fluka, Switzerland) and intensified with $3 \% \mathrm{CuSO}_{4}$ solution for 5 minutes. Sections were counterstained with Meyer's haematoxylin (Merck, Germany) or light green (BDH Chemicals Ltd., UK), dehydrated, and mounted in DPX (Fluka).

2.6. Quantitative PCR. Genomic DNA was extracted from the cells using the silica-gel-membrane-based DNeasy Tissue Kit (Qiagen, Germany). Telomere length measurement was performed by the qPCR assay according to method described by Cawthon [20] with small modifications. Briefly, the telomere repeat copy number to single-gene copy number $(\mathrm{T} / \mathrm{S})$ ratio was determined using the equation: $\mathrm{T} / \mathrm{S}=2^{-\Delta \mathrm{Ct}}$ (where $\Delta \mathrm{Ct}=\mathrm{Ct}_{\text {telomere }}-\mathrm{Ct}_{\text {single-copy gene }}$ ). Then, the $\mathrm{T} / \mathrm{S}$ for each sample was normalized to $\mathrm{T} / \mathrm{S}$ value of a reference DNA sample to standardize between different runs, that is, $-\Delta \Delta \mathrm{Ct}$ was calculated for each sample. This value is proportional to the average telomere length of the evaluated sample. 36B4, encoding acidic ribosomal phosphoprotein $\mathrm{P} 0$, was used as the single copy gene. Telomere and 36B4 gene PCRs were always done in separate 96-well plates with each sample run in triplicate in the same well position on an ABI 7500 HT Detection System (Applied Biosystems, USA). Each $20 \mu \mathrm{L}$ reaction consisted of $20 \mathrm{ng}$ DNA, $1 \times$ SYBR Green master mix (Applied Biosystems), and $200 \mathrm{nM}$ telomere forward primer (CGG TTT GTT TGG GTT TGG GTT TGG GTT TGG GTT TGG GTT), $200 \mathrm{nM}$ telomere reverse primer (GGC TTG CCT TAC CCT TAC CCT TAC CCT TAC CCT TAC CCT). For 36B4 gene PCR the following primer pairs were used: 36B4u, CAG CAA GTG GGA AGG TGT AAT CC; 36B4d, CCC ATT CTA TCA TCA ACG GGT ACA A. The DNA quantity standards were derived from serial dilutions of a reference DNA sample to produce three final concentrations $(0.02,0.2$, and $2.0 \mathrm{ng} / \mu \mathrm{L})$. In each run, a standard curve and a negative control (water) were included. Cycling conditions (for both telomere and 36B4 products) 


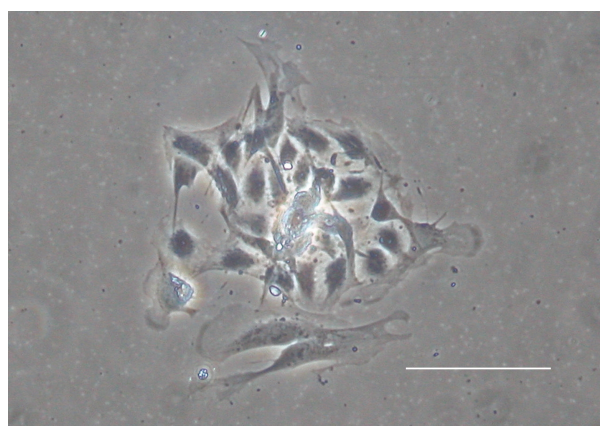

(a)

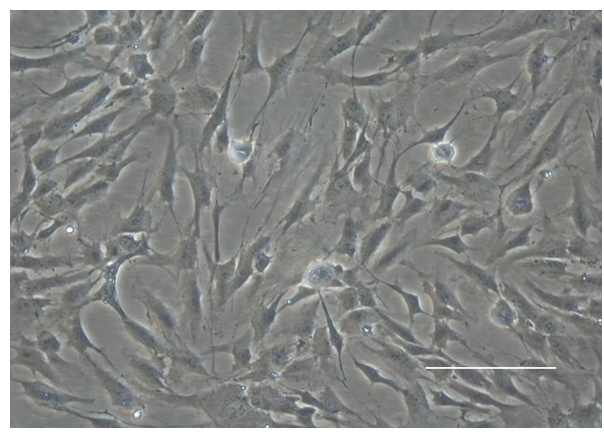

(b)

FIGURE 1: Phase contrast micrograph of DPSCs in culture. (a) Small colonies (CFU-F) formed by DPSCs appeared in primary culture after 3 days in vitro. (b) Spindle-shaped morphology of cells in culture reaching $70 \%$ confluence. Scale bars $50 \mu \mathrm{m}$.

were 10 minutes at $95^{\circ} \mathrm{C}$, followed by 40 cycles of $95^{\circ} \mathrm{C}$ for $15 \mathrm{~s}$ and $60^{\circ} \mathrm{C}$ for 1 minute. Following amplification, a dissociation curve was done to confirm the specificity of the reaction. Standard and dissociation curves were generated with the ABI Prism 7500 SDS software. $R^{2}$ for each standard curve was $>0.98$.

The Du145 prostate cancer cells were cultured as described previously [21] and served as a control for comparison of length of short telomeres with relative T/S value of DPSCs.

2.7. Statistical Analysis. The relationship between average telomere length and selected parameters was performed by correlation analysis using statistic software GraphPad Prism 5.01 (San Diego, USA). A value of $P<.05$ was considered statistically significant.

\section{Results}

3.1. DPSC Kinetics. From each patient, only one tooth was extracted. From the dental pulp isolated from the single tooth we established one DPSC line. Although each enzymatic digestion of the dental pulp yielded only several tens of adhering cells, after two to three days in vitro (DIV) the poorly differentiated cells started to form small colonies. DPSCs actively migrated, proliferated, and formed new colonies (Figure 1(a)). By 6-7 DIV, the cells reached 70\% confluence in monolayer and they changed their shape. The cells elongated, their bodies exhibited fibroblast-like morphology. Despite their elongated morphology most cells had flattened and triangular body from which few (usually three or more) slim cytoplasmic processes emanated. At all times the culture contained some rounded dividing cells with more or less retracted processes. All these DPSCs constituted a homogenous monolayer population (Figure 1(b)).

During passaging, the cell viability, diameter distribution, and cell numbers were measured. Cells taken from culture at passages p5-p15 had $15.1 \pm 3.4 \mu \mathrm{m}$ in diameter; p25-p35 cells had averaged size $15.9 \pm 4.9 \mu \mathrm{m}$. Cell kinetics characterization with cumulative population doublings and doubling time gave evidence of changes occurring in the growth rate of DPSC lines during long-term cultivation (Figure 2). All DPSC lines were able to grow beyond Hayflick's limit. The highest population doubling number reached in our DPSC lines was 81; after this time point, the growth of the DPSC line was interrupted for technical reasons. Initially DPSCs showed increased proliferative activity. Doubling time measured in DPSC lines during initial passages p2-p5 was $23.0 \pm 0.8$ hours and $24.9 \pm 1.4$ hours (arithmetic mean \pm S.E.M. in males and females, resp.). With the increasing number of passages, the doubling time of cultured DPSCs increased as well (Figures 2(b) and 2(c)). At later passages p16-p20, the cell doubling time slowed down to $59.9 \pm 7.3$ hours and $39.1 \pm 3.7$ hours in cells derived from males and females. Interestingly, there were significant differences in doubling time when comparing values from p16-p20 between male versus female DPSC lines $(P<$ $.05)$ while difference in initial passages were insignificant $(P=.30)$. Trypan blue exclusion test demonstrated the cell viability remained well preserved and did not drop below $90 \%$ in all cell cultures tested. Cytogenetic screening carried out regularly at distinct passages in all DPSC lines revealed neither any chromosomal abnormality nor any signs of degeneration or spontaneous differentiation.

3.2. Antigenic Profile of DPSCs. Our characterization of DPSCs included determination of their antigenic profile. Flow cytometric analysis revealed that the cells did not express haemopoietic markers CD34 and CD45. Endothelial cell markers CD31, CD106, and CD146 were also low; moderate expression was observed in CD105. On the contrary, DPSCs expressed high levels of mesenchymal markers CD29, CD44, CD73, CD90, and CD166. Data received from comparison of phenotypes of cells yielded from different passages were summarized in Figure 3 and provided evidence of a stable phenotype of DPSC lines. Moreover, immunofluorescent identification (Figures 4(a)$4(\mathrm{~h})$ ) confirmed strong expression of mesenchymal markers STRO-1 and vimentin in all cultures of DPSCs. STRO1 was concentrated on the membrane over the cell body and large cytoplasmic processes. Protein vimentin was distributed in the same density in filamentous network that entered regularly the body and both flattened and 


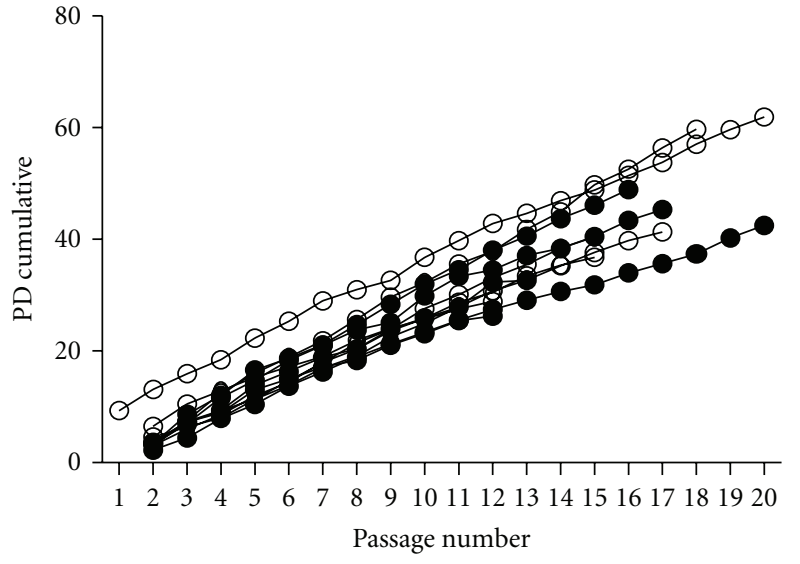

(a)

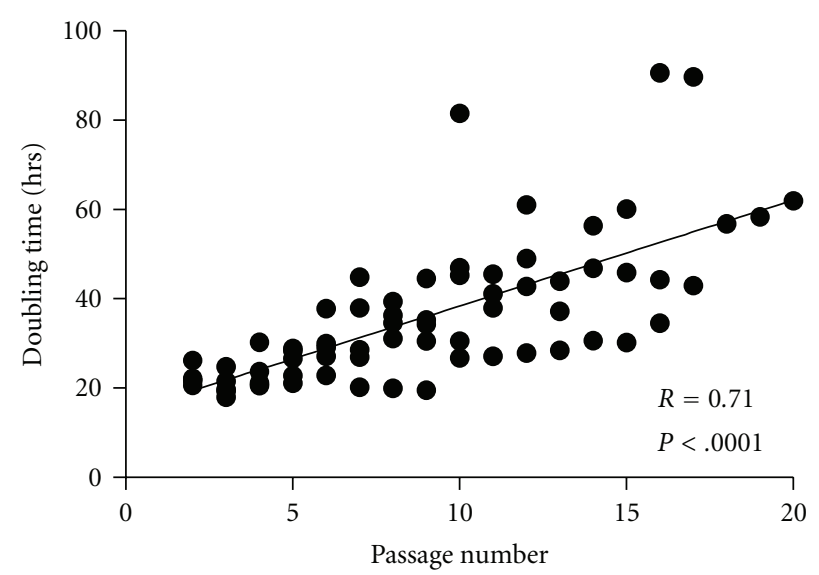

(b)

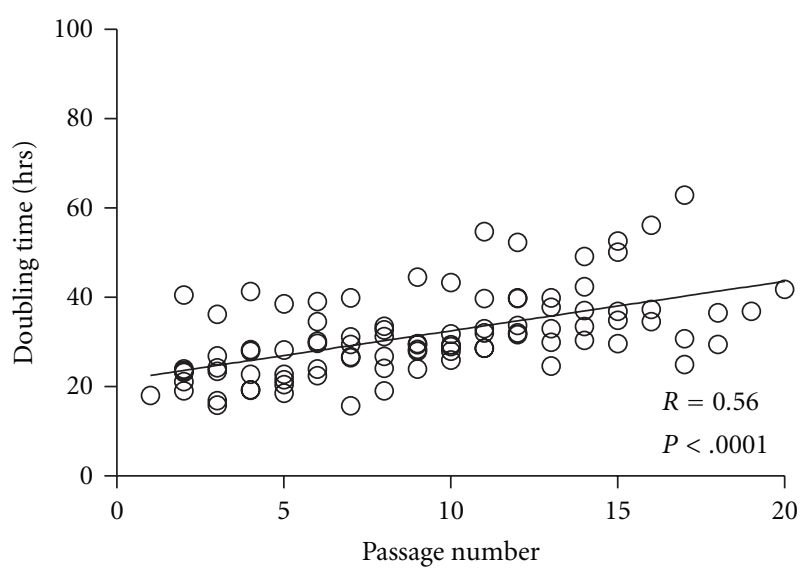

(c)

FIGURE 2: The growth kinetics of DPSC lines. (a) Cumulative population doublings of 11 DPSCs lines are shown. The cultures were derived from individual patients and passaged as described in Section 2. The number of population doublings was calculated as follows: PD = $\left(\log _{10} n_{f}-\log _{10} n_{i}\right) / 0.301$, where $n_{i}$ is the initial number of cells and $n_{f}$ is the final number of cells at each passage. (b, c) Data of doubling time reached by DPSCs from male (b) and female (c) donors at different passages in culture. The linear regression line best fitting the data is shown, $R=0.71, P<.0001$. The doubling time was calculated from the formula DT $=\log _{10} 2 T / \log _{10} n_{f}-\log _{10} n_{i}$, where $T$ is time in hrs. $R=0.56, P<.0001$. Filled circles indicate males and open circles indicate females.

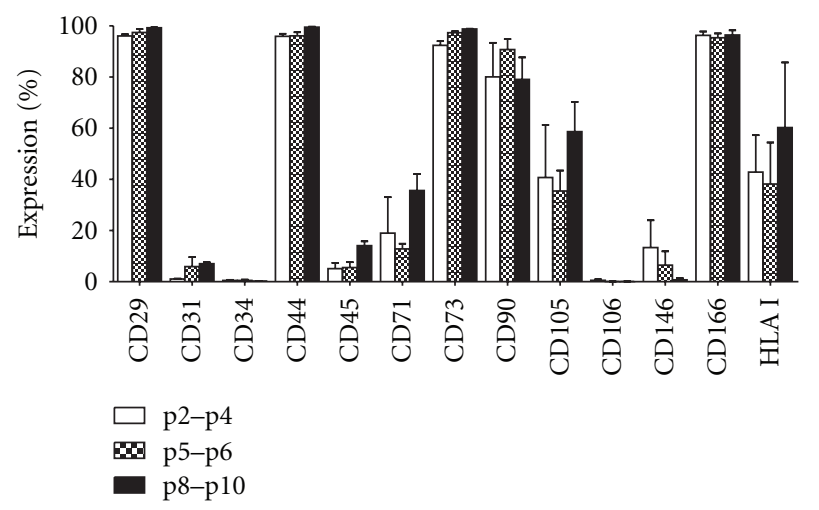

FIGURE 3: Flow cytometric analysis of cell surface marker expression in DPSCs at different passages. Results are expressed as arithmetic mean \pm SEM.

slim processes. Signal slightly increased around the cell nucleus. Immunolocalisation of intermediate filament nestin showed variable pattern of expression in DPSCs. In most cells nestin formed tiny filamentous network that was homogenously distributed throughout cell body and concentrated around the cell nucleus. However, in smaller spherical cells that rounded during the mitotic division the immunoreactivity increased so much that it obscured the nucleus and cytoplasmic filaments were not well recognizable. Additionally, we detected several stem cell markers to be stably expressed in DPSCs. CXCR4 immunostaining was observed in both a nuclear and cytoplasmic pattern. A uniform nuclear and faint cytoplasmic staining pattern was observed in Sox 2 immunocytochemistry. Sox $2^{+}$signal in cell cytoplasm was likely associated with rough endoplasmic reticulum being localized in the vicinity to the nucleus and entering the main cytoplasmic processes; signal intensity increased in dividing cells. Immunodetection of nucleostemin localised strong signals to several nodular structures within the nucleus of interphasic cells. Strong punctate immunolabelling of CD90 was present on the plasma membrane of all DPSCs. CD166 was localised 


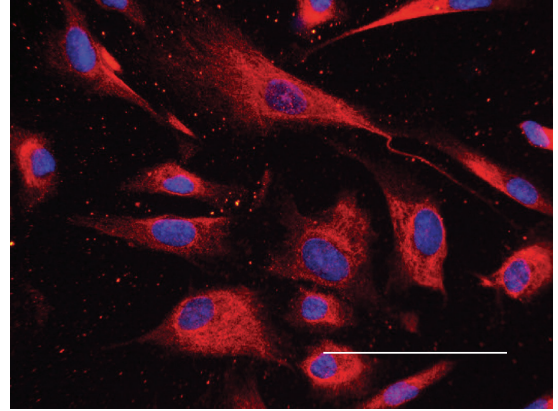

(a)

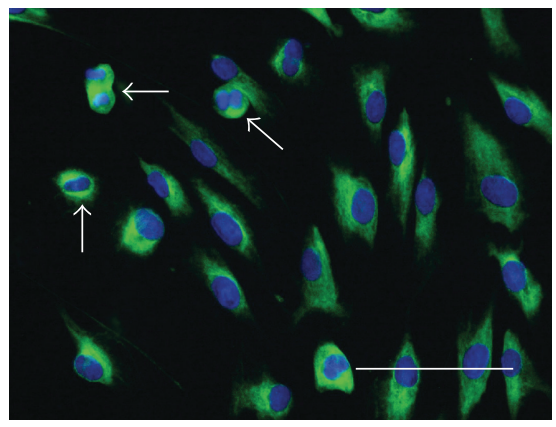

(c)

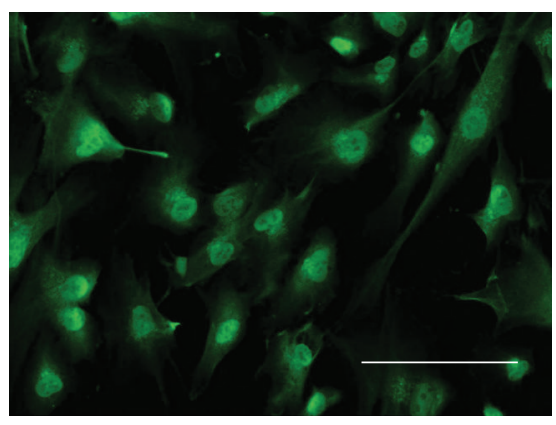

(e)

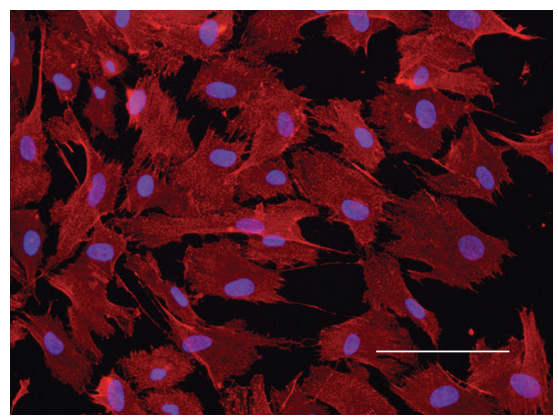

(g)

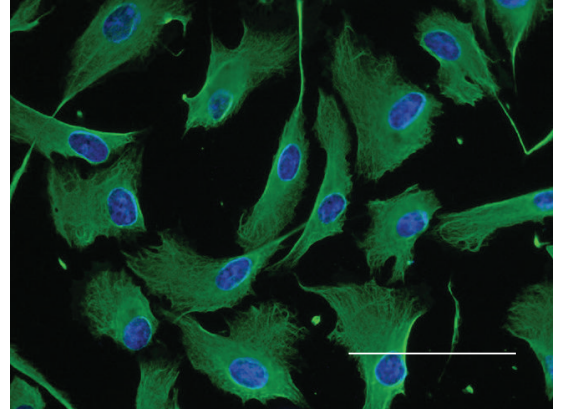

(b)

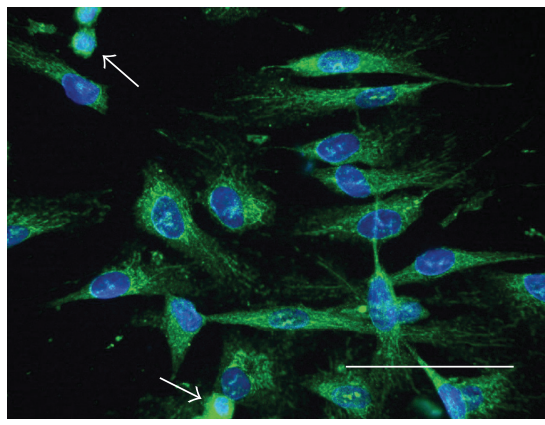

(d)

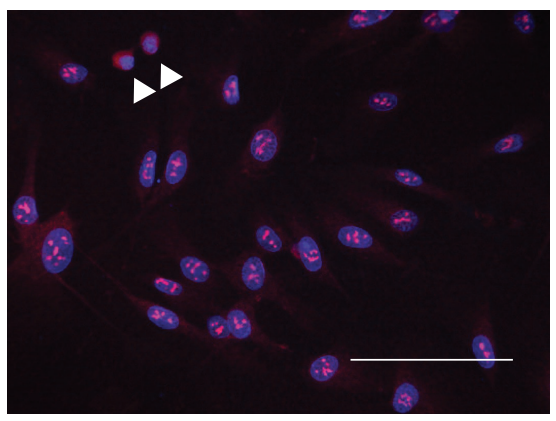

(f)

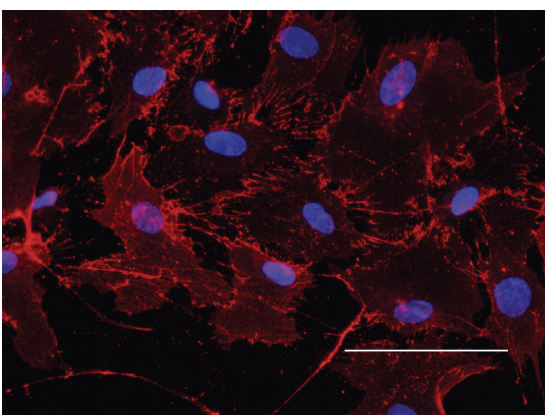

(h)

FIGURE 4: Immunocytochemical detection of analyzed markers in cultured DPSCs. (a) STRO-1 expression was readily detectable in all cells. (b) Immunostaining of vimentin revealed a regular filamentous cytoskeletal network within the cells with signal accentuation in perinuclear region. (c) Nestin expression appeared in the cell body, however, in cytoplasmic outgrowths the signal was lower but still distinguishable. Intensive signal is localized in dividing cells. (d) CXCR4 was localized mainly in the cytoplasm, namely, in its perinuclear area; some signal was also distinguishable within the cell nuclei. (e) Sox 2 was distributed mainly in cell nuclei; signal in perinuclear cytoplasm likely reflects synthesis of this transcription factor in endoplasmic reticulum. (f) Nucleostemin was observed in nodular structures in cell nuclei; in mitotic cells or cells that had just finished cytokinesis (arrowheads) immunoreactivity was lost from the nucleus and distributed diffusely. (g) CD90 immunofluorescence showed homogenous dot-like membrane staining pattern. (h) CD166 was localised in membrane of all DPSCs contouring the cell edges. Nuclei were counterstained with DAPI. Arrows indicate dividing cells. Scale bars $50 \mu \mathrm{m}$. 


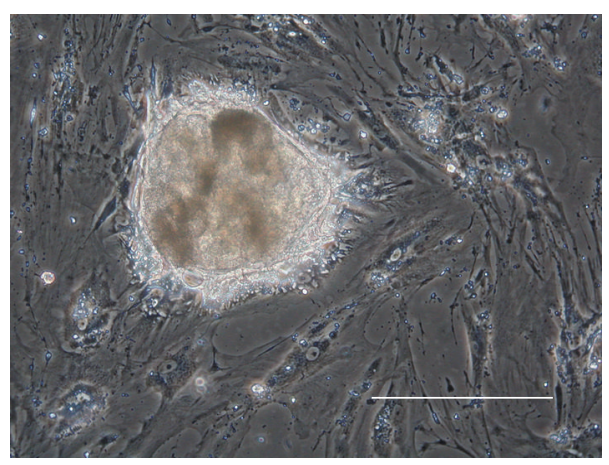

(a)

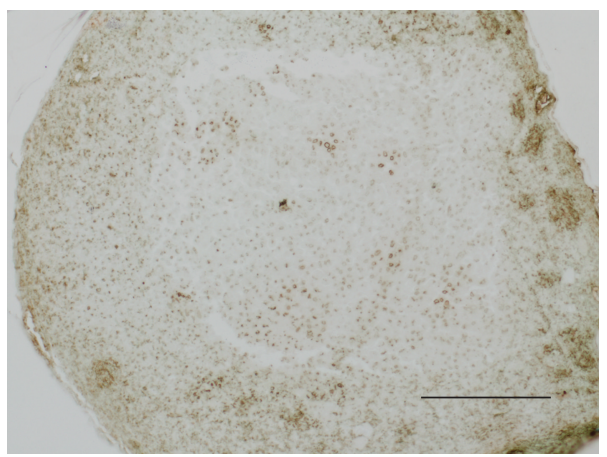

(c)

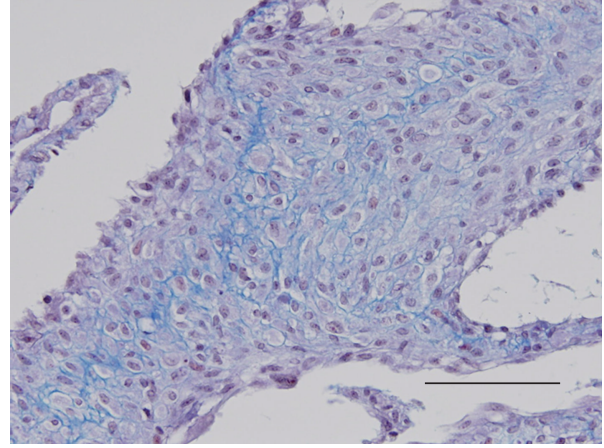

(b)

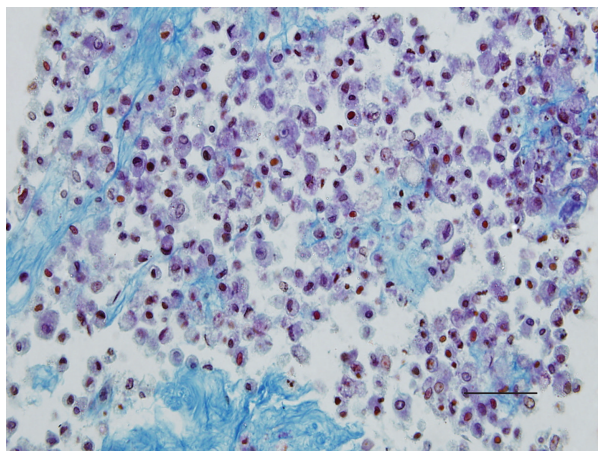

(d)

Figure 5: Osteogenic and chondrogenic potential of DPSCs. (a) Phase contrast micrograph of osteogenic nodule after 4 week-cultivation in differentiation medium. (b) Histological examination revealed multilayered structure consisting of osteoblast-like cells surrounded by extracellular matrix containing collagen fibres; Ladewig blue trichrome. (c) Immunoperoxidase histochemistry of osteonectin confirmed the presence of this bone-specific glycoprotein that links minerals to collagen within the micromass pellets. (d) Chondrogenic micromass bodies were composed of cells and extracellular matrix. Alcian blue staining confirmed the presence of sulphated acidic glycosaminoglycans, a principal component of cartilaginous ground substance. Scale bars (a)-(b) $100 \mu \mathrm{m}$, (c) $200 \mu \mathrm{m}$, (d) and $50 \mu \mathrm{m}$.

to the cell surface of all DPSCs; the signal was intense especially in tiny and flattened cell edges tracing well the cell contours.

Fluorescent co-staining with DAPI confirmed that DPSCs were mononucleated. Within their cell body the nucleus was localized eccentrically usually in the pole opposite to the largest cytoplasmic process. The size of nuclei slightly varied likely in dependence on the cell cycle phase. Almost $7 \%$ of cells were in G2/M phase, $36 \%$ in S phase and the rest in G1 phase of the cell cycle.

3.3. DPSC Multipotency. To test DPSC multipotency, the cells were exposed to conditions that initiate osteo-, chondro-, and adipogenesis. Osteoinductive potential of DPSCs has been investigated at high density cultures that resulted in cell aggregation in osteogenic nodules (Figure 5(a)) or micromass pellets. Histological examination of both multilayer nodules and osteo-pellets performed after 3-4 weeks of cultivation revealed that these threedimensional structures were formed by osteoblast-like cells and deposits of extracellular matrix. Basophilic cells that covered the outer surfaces were smaller than the cells that were entrapped within the matrix. Histochemical staining confirmed the presence of collagen fibrils (Figure 5(b)) and osteonectin (Figure 5(c)), two principal bone-related proteins, within the matrix.

To trigger early chondrogenic differentiation, we utilized micromass cell culture technique and exposed aggregated cells to chondrogenic medium. During two weeks in vitro, DPSCs in a high density culture system gave rise to threedimensional chondrogenic micromass bodies. Cells inside these bodies retracted their processes, assumed spherical to oval morphology and started to produce extracellular matrix (Figure 5(d)). Areas containing the matrix that accumulated between the cells reached sizes above $40 \mu \mathrm{m}$. Mostly these areas remained devoid of the cells although occasionally the cells became entrapped within the cartilaginous matrix. Alcian blue staining proved apparent de novo synthesis of strongly sulphated acidic glycosaminoglycans, a principal component of cartilaginous ground substance. These alcian blue-positive areas were surrounded by foci of densely accumulated chondroblastic cells. Presence of cellular regions and regions filled with cartilaginous matrix made chondrogenic micromass bodies less compact than osteogenic pellets. RT PCR analysis of micromass bodies performed by Karbanova et al. [22] gave evidence of synthesis of cartilage specific collagen II and aggrecan transcripts. 


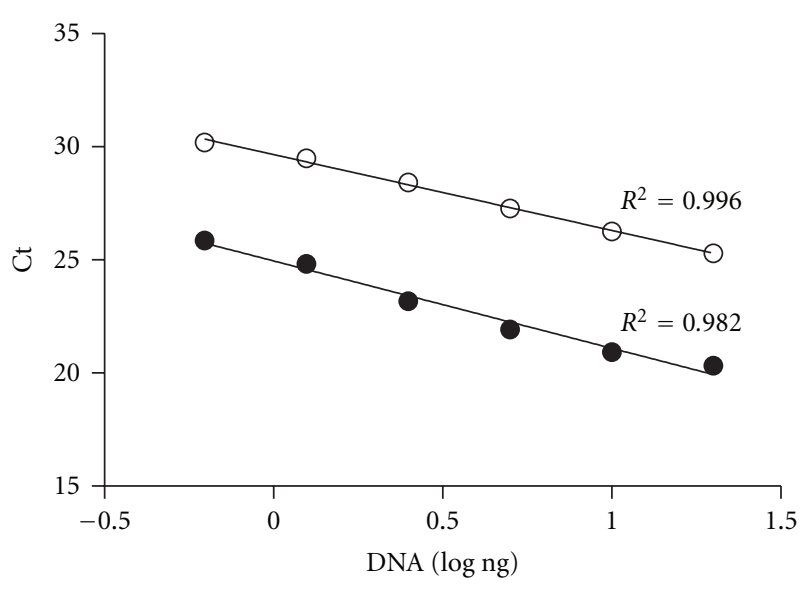

FIGURE 6: A standard curve generated from a reference DNA sample serially diluted by dilution factor 2 to produce six concentrations of DNA ranging from 0.625 to $20 \mathrm{ng}$ of DNA per reaction. Shown inside are the correlation regression coefficients $\left(R^{2}\right)$ of Ct versus the amount of DNA. Filled circles indicate telomeres and open circles indicate 36B4 control.

DPSCs in a monolayer cultured under conditions supporting adipogenesis continued to proliferate and grow in few layers. However, despite different adipogenic assays tested, we neither observed formation of vacuoles nor accumulation of lipid droplets in the cell cytoplasm in any DPSC line.

3.4. Telomere Length Measurement in DPSCs. In order to analyze the effect of serial passages on relative telomere length in DPSC lines, we extracted DNA from DPSC lines harvested at different passages from culture and processed them using quantitative real-time PCR. In each plate, a standard curve was generated from a reference DNA sample serially diluted by dilution factor 2 to produce six concentrations of DNA ranging from 0.625 to $20 \mathrm{ng}$ of DNA per reaction (Figure 6 ). The $R^{2}$ for each standard curve was $>0.98$. Relative $T / S$ ratio was calculated in DNA samples from cultured cells by correction of T/S ratio detected in evaluated sample by the T/S value of reference sample. For comparison of T/S values with telomere length we processed DNA from human prostate cancer Du145 cells. This adenocarcinoma cell line has been reported to have a short mean telomere length of $2.8 \mathrm{~kb}$ [21] and this average telomere length remained stable throughout passages [23]. In our assay for telomere length measurement, relative $\mathrm{T} / \mathrm{S}$ ratio in Du145 cells was equal to 0.13 . This value was more than twice lower than values measured in any DPSC line from late passages.

DPSCs included in this analysis were harvested from passages $\mathrm{p} 2$ to $\mathrm{p} 16$, that is, they reached 16 to 50 population doublings. DPSC lines derived from different patients showed values of relative $T / S$ which were within the interval 0.3 to 1.33 . Despite this interindividual variation among patients the trend in the change of relative T/S ratio over passages in time was apparent; DPSC lines showed an overall and significant decrease in relative telomere length with increasing passage number $(P<.0001)$ (Figure $7(a))$. Also changes in doubling time versus relative telomere length $(\mathrm{T} / \mathrm{S})$ were significant $(P<.05)$ which demonstrated prolongation of doubling time in cells with shortened telomere length (Figure 7(b)). Due to low number of samples taken from patients of the same age group, we were not able to analyze age-related shortening in DPSC telomere length or dependence of telomere length on gender.

\section{Discussion}

In this study, we provide the DPSC characteristics grown in optimal conditions with a reduced level of serum. Our results demonstrate that under these in vitro conditions DPSC lines are capable of long-term cultivation without changing their viability, phenotype, and genotype. DPSCs express many stem cells markers in distinct pattern from other adult stem cells. We report here that DPSCs do not express haemopoietic marker CD34 and CD45. On the other hand they express at high levels mesenchymal markers such as vimentin, STRO-1, CD29, CD44, CD73, CD90, and CD166 and thus DPSCs are related to mesenchymal stem cells isolated from the bone marrow although they differ in some other markers. Expression of pluripotent embryonic stem cell marker Sox-2 confirms a primitive nature of DPSCs. Neural stem cell markers such as nestin and nucleostemin observed by us in DPSCs may reflect the neural crest origin of the dental pulp. DPSCs have been also described to express astroglial marker GFAP [24]. We also described distribution of the selected markers within DPSCs as well as changes in their expression during the cell cycle.

Another feature of adult stem cells is their multilineage potential. DPSCs have a potential to create a dental-pulp complex after transplantation into immunocompromised mice and in vitro they exhibit ability to produce mineralized bony tissues $[24,25]$. Since dental tissues are very specific structures that could be generated only in in vivo assays, we restricted identification of stem cell multipotency to in vitro assays utilized in the study of mesenchymal stem cells. Our data demonstrated a clear osteogenic and chondrogenic potential of DPSCs. On the other hand, we were not able to trigger adipogenesis from DPSCs. Nevertheless these findings are in agreement with observation of Gronthos et al. [7] who expanded DPSCs from single cell clones and demonstrated their osteogenic properties and no formation of lipid laden adipocytes. In their later study Gronthos et al. [24] reported DPSCs were able to generate adipocytes albeit unwillingly. In this study, we also documented DPSCs had chondrogenic potential. Such potential for osteo-, chondro-, and adipogenesis may seem to be surprising because these tissues are not resident components of the dental pulp cavity or its surrounding tissues. Nevertheless osteo- and chondro-genic repertoire may be explained by ectomesenchymal origin of the dental pulp. The neural crest contributes to building head skeleton, for example, face bones and membranous bones of the skull vault, to visceral cartilages as reviewed by Santagati and Rijli [26] and also to subsets of adipocytes, namely, in the ear region 


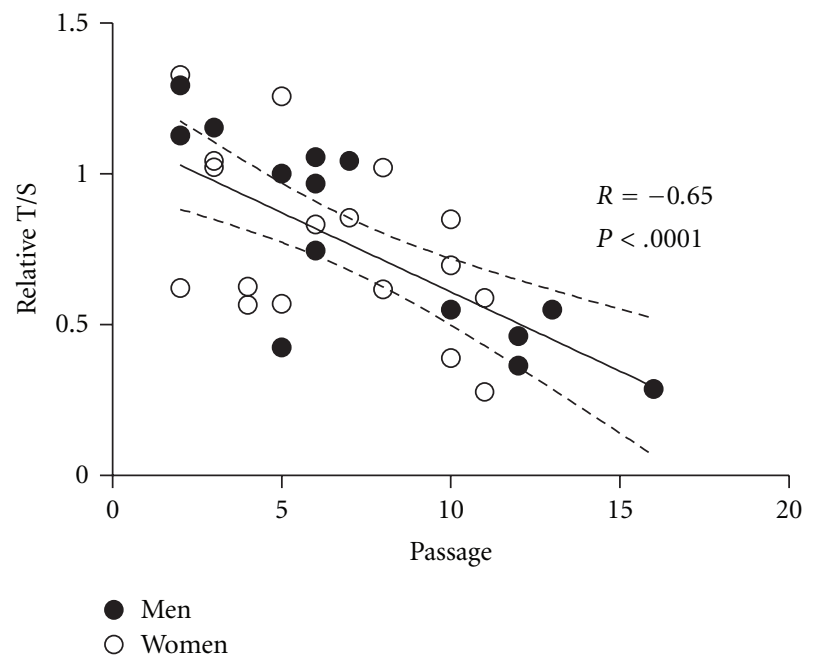

(a)

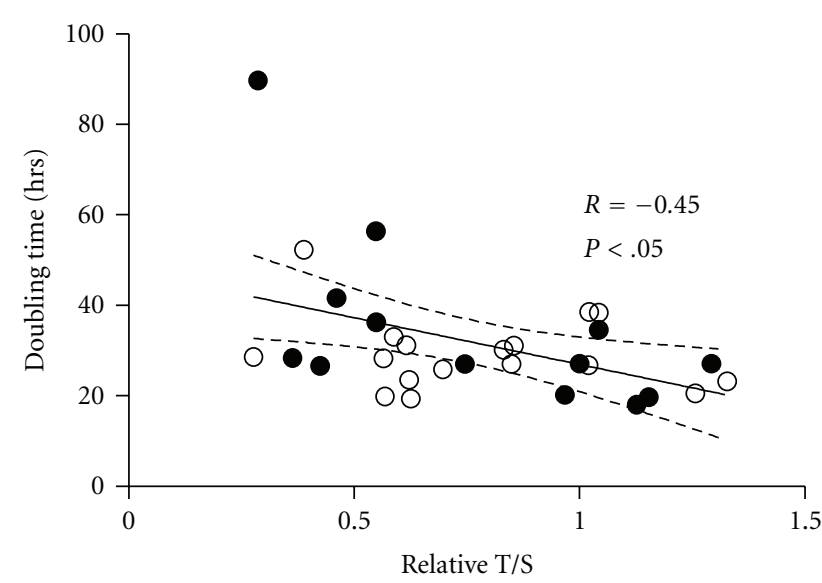

- Men

Women

FIgURE 7: Plot of average telomere length (relative T/S) against passage number and doubling time versus T/S. (a) Relative telomere length expressed as ratio of T/S by quantitative real-time PCR analysis shows a decrease in T/S with increasing passage numbers. (b) Plot of doubling time in hours against relative telomere length (T/S) and regression line. The correlation coefficients of the linear regression line best fitting the data are shown. Filled circles indicate males $(n=5$ individuals) and open circles indicate females $(n=6)$.

[27]. Similarly to the neural crest stem cells which have broader differentiation potential, DPSCs show in distinct differentiation regimes, potential to generate multiple cell types including neural, glial, endothelial, and smooth muscle cells (see [22], unpublished results).

In addition to expression of stem cell markers by DPSCs and proof of their multipotency, we documented their extensive proliferative capacity in long-term culture. On the contrary to somatic cells, the stem cells may be propagated over Hayflick's limit. Replicative capacity in somatic cells is restricted due to a steady decline in telomere length with each round of DNA replication [28] that ultimately stops cell division and causes senescence. The stem cells gained an advantage over somatic cells and evolved mechanisms that could counteract telomere loss; they express a specific ribonucleoprotein enzyme, telomerase, which is required for telomere length maintenance. As a result functional stem cells could be isolated from tissues of elderly people [29] where these cells still perform their vital functions associated with tissue maintenance and regeneration. Serial transplantation experiments with mouse haemopoietic stem cells gave evidence that functional capacity of stem cells exceeds beyond lifespan of the organism since the stem cells may be successfully transplanted in several rounds [15]. Observations that, for example, embryonic stem cells can be propagated in vitro for decades and remain stable led to speculations on stem cell immortality.

When monitoring parameters related to cell kinetics in time we noticed some characteristic changes in human DPSCs that could be summarized as a decrease of their proliferation rate during long-term cell cultivation and increase of their doubling time. Similar findings were also published by Huang et al. [9] who reported rhesus DPSCs had a high proliferation rate during early passages from establishment of the cells lines which decreased gradually during cultivation. Interestingly, we observed that doubling time of cell lines derived from males showed significantly larger prolongation when compared with data taken from female DPSC lines. Such observation may reflect a larger resistance of female stem cells described, for example, by Crisostomo et al. [30], a longer life expectancy of females or exposure of a source tissue to estrogen, which can upregulate telomerase [31]. Nevertheless, the overall increase in doubling time indicates stem cell ageing that is linked with a decrease of their regenerative capacity and with ageing of tissues.

In order to explain if the above mentioned changes in DPSC kinetics are related to telomere shortening, we analyzed telomere length in cells harvested from culture at different passages. We utilized quantitative real-time PCR assay that allows the rapid measurement of the telomere-tosingle copy gene (T/S) ratio, which has been demonstrated to be proportional to the average telomere length [20]. Results obtained with quantitative PCR are comparable with other quantitative methods, such as flow-FISH and Southern blotting [32]. Our data provided a clear evidence of telomere shortening which was detected by us when comparing relative telomere length of DPSCs harvested at different time intervals from culture. We also demonstrated that a decrease in relative $T / S$ in time was associated with slowing down doubling time of DPSCs. We measured relative telomere length in cells obtained from passages $\mathrm{p} 2$ to $\mathrm{p} 16$ which spanned approximately 2 months in vitro during which cells extensively duplicated. By passage 16 the cells reached in average 40 population doublings which indicated a $10^{12}$-increase in cell number. Such remarkable ex vivo expansion on the one hand might be useful for obtention of 
large numbers of desired stem cells necessary for treatment of patients by cell transplantation but on the other hand might be associated with stressful conditions that lead to a decrease of replicative capacity or ultimately to stem cell exhaustion.

It is believed that telomerase activity is responsible for at least partial restoration of telomere DNA strands. Interestingly the levels of telomerase activity may differ among stem cell populations which likely reflect their different hierarchical origin. Embryonic stem cells have high telomerase activity which makes them virtually immortal [17]. Although telomerase has been described in distinct populations of adult tissue-specific stem cells incl. haemopoietic $[15,33]$, liver [34], epidermal [16], intestinal [35], and neural [36], this activity is insufficient to completely prevent telomere loss. This might be the case of DPSCs too. Sonoyama et al. [18] detected telomerase activity in human DPSCs isolated from the first three passages that was larger than activity of bone marrow stromal stem cells. However, the authors neither determined telomere dynamics nor telomerase activity at later passages.

\section{Conclusions}

In conclusion, we confirmed that extensive in vitro proliferation of human DPSCs was associated with telomere attrition which significantly correlated with prolongation of DPSC doubling time. These findings cover several relevant aspects. First, can the ratio of telomere shortening in stem cells be attenuated by less stressful in vitro conditions? Chronic stress and oxygen radicals accelerate loss of telomeres and diminish the individual's lifespan [37]. Second, a progressive telomere shortening diminishes transplantation capacity of stem cells making them less suitable for therapeutic applications. If ex vivo expansion causes shrinkage of telomeres in tissuespecific stem cells other alternative procedures allowing large yields of stem cells should be preferred. By introducing genes encoding pluripotent transcription factors into fibroblasts, Takahashi and Yamanaka [38] laid basis for generation of induced pluripotent stem cells. Despite the advantage that such cells may be isolated from somatic cells of old patients, their reprogramming is associated with full re-elongation of telomeres to sizes comparable with early embryonic cells [17]. Finally, determination of telomere length represents an important biomarker that should be taken into consideration when characterizing the status and replicative age of stem cells prior their utilization in treatment of human patients.

\section{Acknowledgments}

The authors thank Mrs. Helena Rückerova, Mrs. Hana Hollerova, Mrs. Magda Vobornikova, and Mrs. Jana Hoskova for their skillful technical assistance. This work was supported by Grant Projects NR 9182-3 from the Internal Grant Agency of the Ministry of Health and MSM 0021620820 from the Ministry of Education of the Czech Republic.

\section{References}

[1] M. J. Evans and M. H. Kaufman, "Establishment in culture of pluripotential cells from mouse embryos," Nature, vol. 292, no. 5819, pp. 154-156, 1981.

[2] N. Strelchenko, O. Verlinsky, V. Kukharenko, and Y. Verlinsky, "Morula-derived human embryonic stem cells," Reproductive BioMedicine Online, vol. 9, no. 6, pp. 623-629, 2004.

[3] G. Kögler, S. Sensken, J. A. Airey et al., "A new human somatic stem cell from placental cord blood with intrinsic pluripotent differentiation potential," Journal of Experimental Medicine, vol. 200, no. 2, pp. 123-135, 2004.

[4] B. A. Reynolds, W. Tetzlaff, and S. Weiss, "A multipotent EGF-responsive striatal embryonic progenitor cell produces neurons and astrocytes," Journal of Neuroscience, vol. 12, no. 11, pp. 4565-4574, 1992.

[5] D. J. Prockop, "Marrow stromal cells as stem cells for nonhematopoietic tissues," Science, vol. 276, no. 5309, pp. 7174, 1997.

[6] A. P. Beltrami, L. Barlucchi, D. Torella et al., "Adult cardiac stem cells are multipotent and support myocardial regeneration," Cell, vol. 114, no. 6, pp. 763-776, 2003.

[7] S. Gronthos, M. Mankani, J. Brahim, P. G. Robey, and S. Shi, "Postnatal human dental pulp stem cells (DPSCs) in vitro and in vivo," Proceedings of the National Academy of Sciences of the United States of America, vol. 97, no. 25, pp. 13625-13630, 2000.

[8] J. Suchanek, T. Soukup, R. Ivancaková et al., "Human dental pulp stem cells_-isolation and long term cultivation," Acta Medica (Hradec Kralove), vol. 50, no. 3, pp. 195-201, 2007.

[9] A. H.-C. Huang, B. R. Snyder, P.-H. Cheng, and A. W. S. Chan, "Putative dental pulp-derived stem/stromal cells promote proliferation and differentiation of endogenous neural cells in the hippocampus of mice," Stem Cells, vol. 26, no. 10, pp. 2654-2663, 2008.

[10] J. A. Knoblich, "Mechanisms of asymmetric cell division during animal development," Current Opinion in Cell Biology, vol. 9, no. 6, pp. 833-841, 1997.

[11] Y.-Y. Jang and S. J. Sharkis, "A low level of reactive oxygen species selects for primitive hematopoietic stem cells that may reside in the low-oxygenic niche," Blood, vol. 110, no. 8, pp. 3056-3063, 2007.

[12] M. Ramalho-Santos, S. Yoon, Y. Matsuzaki, R. C. Mulligan, and D. A. Melton, "'Stemness": transcriptional profiling of embryonic and adult stem cells," Science, vol. 298, no. 5593, pp. 597-600, 2002.

[13] C. W. Greider, “Telomere length regulation," Annual Review of Biochemistry, vol. 65, pp. 337-365, 1996.

[14] J. M. Y. Wong and K. Collins, "Telomere maintenance and disease," Lancet, vol. 362, no. 9388, pp. 983-988, 2003.

[15] R. C. Allsopp, G. B. Morin, R. DePinho, C. B. Harley, and I. L. Weissman, "Telomerase is required to slow telomere shortening and extend replicative lifespan of HSCs during serial transplantation," Blood, vol. 102, no. 2, pp. 517-520, 2003.

[16] I. Flores, M. L. Cayuela, and M. A. Blasco, "Effects of telomerase and telomere length on epidermal stem cell behavior," Science, vol. 309, no. 5738, pp. 1253-1256, 2005.

[17] R. M. Marion, K. Strati, H. Li et al., "Telomeres acquire embryonic stem cell characteristics in induced pluripotent stem cells," Cell Stem Cell, vol. 4, no. 2, pp. 141-154, 2009. 
[18] W. Sonoyama, Y. Liu, D. Fang et al., "Mesenchymal stem cellmediated functional tooth regeneration in Swine," PLOS ONE, vol. 1, no. 1, article no. e79, 2006.

[19] J. Suchanek, T. Soukup, B. Visek, R. Ivancakova, L. Kucerova, and J. Mokry, "Dental pulp stem cells and their characterization," Biomedical Papers, vol. 153, no. 1, pp. 31-36, 2009.

[20] R. M. Cawthon, "Telomere measurement by quantitative PCR," Nucleic Acids Research, vol. 30, no. 10, article no. e47, 2002.

[21] A. Asai, Y. Oshima, Y. Yamamoto et al., "A novel telomerase template antagonist (GRN163) as a potential anticancer agent," Cancer Research, vol. 63, no. 14, pp. 3931-3939, 2003.

[22] J. Karbanova, T. Soukup, J. Suchanek, R. Pytlik, D. Corbeil, and J. Mokry, "Characterization of dental pulp stem cells from impacted third molars cultured in low serum-containing medium," Cells Tissues Organs. In press.

[23] Y. Kageyama, S. Kamata, J. Yonese, and H. Oshima, "Telomere length and telomerase activity in bladder and prostate cancer cell lines," International Journal of Urology, vol. 4, no. 4, pp. 407-410, 1997.

[24] S. Gronthos, J. Brahim, W. Li et al., "Stem cell properties of human dental pulp stem cells," Journal of Dental Research, vol. 81, no. 8, pp. 531-535, 2002.

[25] S. Batouli, M. Miura, J. Brahim et al., "Comparison of stemcell-mediated osteogenesis and dentinogenesis," Journal of Dental Research, vol. 82, no. 12, pp. 976-981, 2003.

[26] F. Santagati and F. M. Rijli, "Cranial neural crest and the building of the vertebrate head," Nature Reviews Neuroscience, vol. 4, no. 10, pp. 806-818, 2003.

[27] N. Billon, P. Iannarelli, M. C. Monteiro et al., "The generation of adipocytes by the neural crest," Development, vol. 134, no. 12, pp. 2283-2292, 2007.

[28] C. B. Harley, A. B. Futcher, and C. W. Greider, "Telomeres shorten during ageing of human fibroblasts," Nature, vol. 345, no. 6274 , pp. 458-460, 1990.

[29] Y. Konishi, K. Lindholm, L.-B. Yang, R. Li, and Y. Shen, "Isolation of living neurons from human elderly brains using the immunomagnetic sorting DNA-linker system," American Journal of Pathology, vol. 161, no. 5, pp. 1567-1576, 2002.

[30] P. R. Crisostomo, T. A. Markel, M. Wang, T. Lahm, K. D. Lillemoe, and D. R. Meldrum, "In the adult mesenchymal stem cell population, source gender is a biologically relevant aspect of protective power," Surgery, vol. 142, no. 2, pp. 215-221, 2007.

[31] K. Kyo, M. Takakura, T. Kanaya et al., "Estrogen activates telomerase," Cancer Research, vol. 59, no. 23, pp. 5917-5921, 1999.

[32] E. Pavesi, F. Avondo, A. Aspesi et al., "Analysis of telomeres in peripheral blood cells from patients with bone marrow failure," Pediatric Blood and Cancer, vol. 53, no. 3, pp. 411416, 2009.

[33] S. J. Morrison, K. R. Prowse, P. Ho, and I. L. Weissman, "Telomerase activity in hematopoietic cells is associated with self-renewal potential," Immunity, vol. 5, no. 3, pp. 207-216, 1996.

[34] Y. Y. Dan, K. J. Riehle, C. Lazaro et al., "Isolation of multipotent progenitor cells from human fetal liver capable of differentiating into liver and mesenchymal lineages," Proceedings of the National Academy of Sciences of the United States of America, vol. 103, no. 26, pp. 9912-9917, 2006.

[35] E. Hiyama, K. Hiyama, N. Tatsumoto, T. Kodama, J. W. Shay, and T. Yokoyama, "Telomerase activity in human intestine," International Journal of Oncology, vol. 9, no. 3, pp. 453-458, 1996.
[36] L. S. Wright, K. R. Prowse, K. Wallace, M. H. K. Linskens, and C. N. Svendsen, "Human progenitor cells isolated from the developing cortex undergo decreased neurogenesis and eventual senescence following expansion in vitro," Experimental Cell Research, vol. 312, no. 11, pp. 2107-2120, 2006.

[37] E. S. Epel, E. H. Blackburn, J. Lin et al., "Accelerated telomere shortening in response to life stress," Proceedings of the National Academy of Sciences of the United States of America, vol. 101, no. 49, pp. 17312-17315, 2004.

[38] K. Takahashi and S. Yamanaka, "Induction of pluripotent stem cells from mouse embryonic and adult fibroblast cultures by defined factors," Cell, vol. 126, no. 4, pp. 663-676, 2006. 

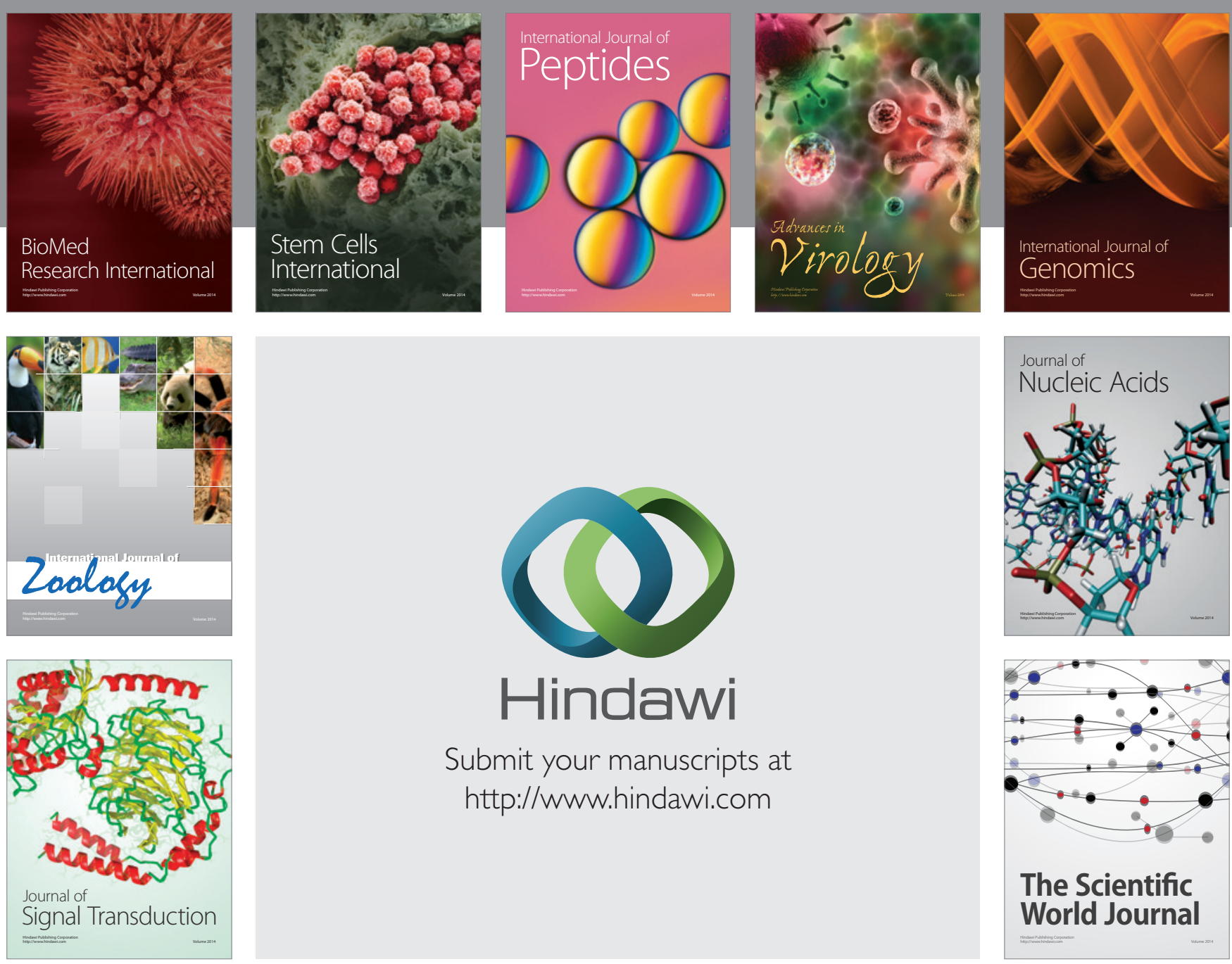

Submit your manuscripts at

http://www.hindawi.com
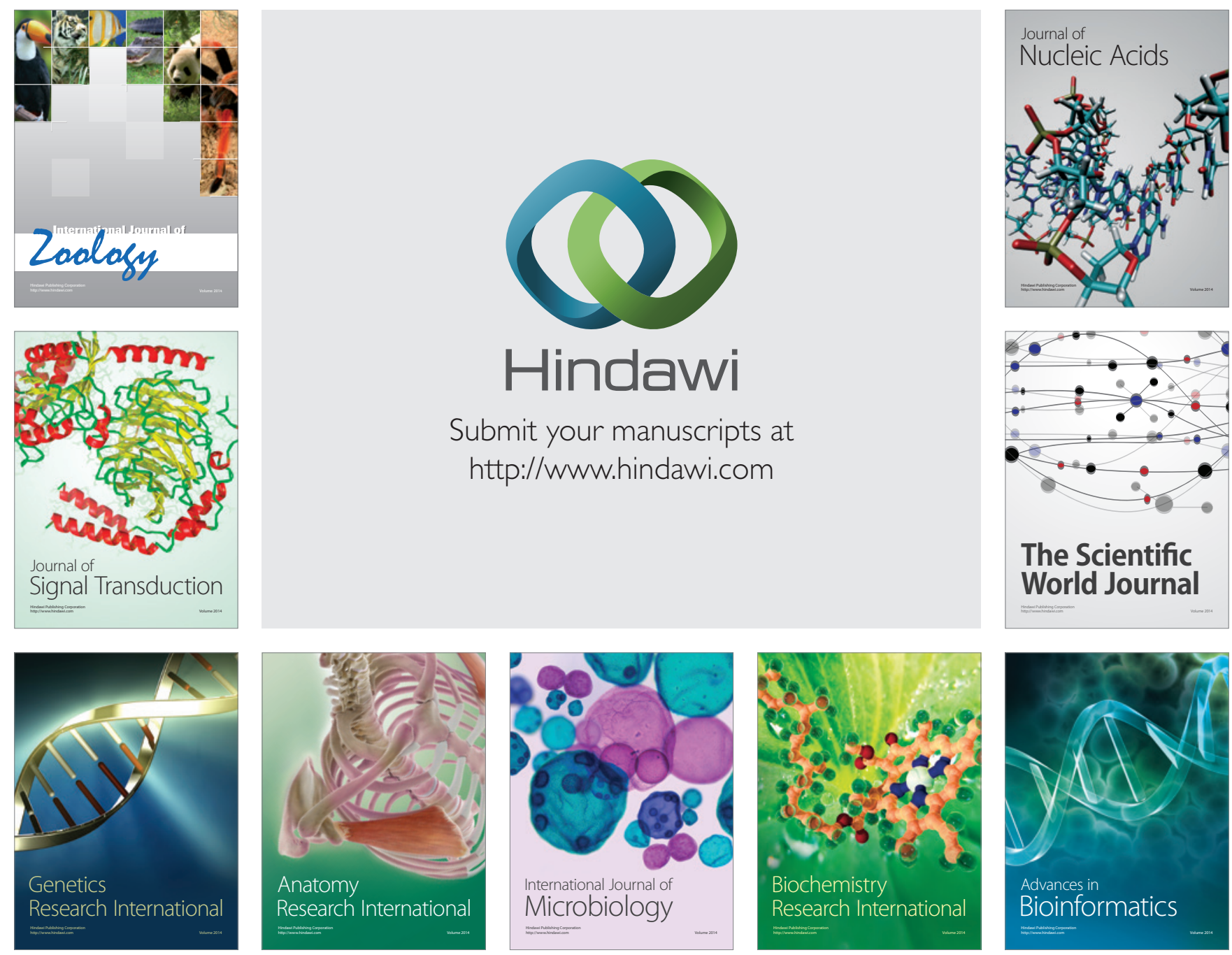

The Scientific World Journal
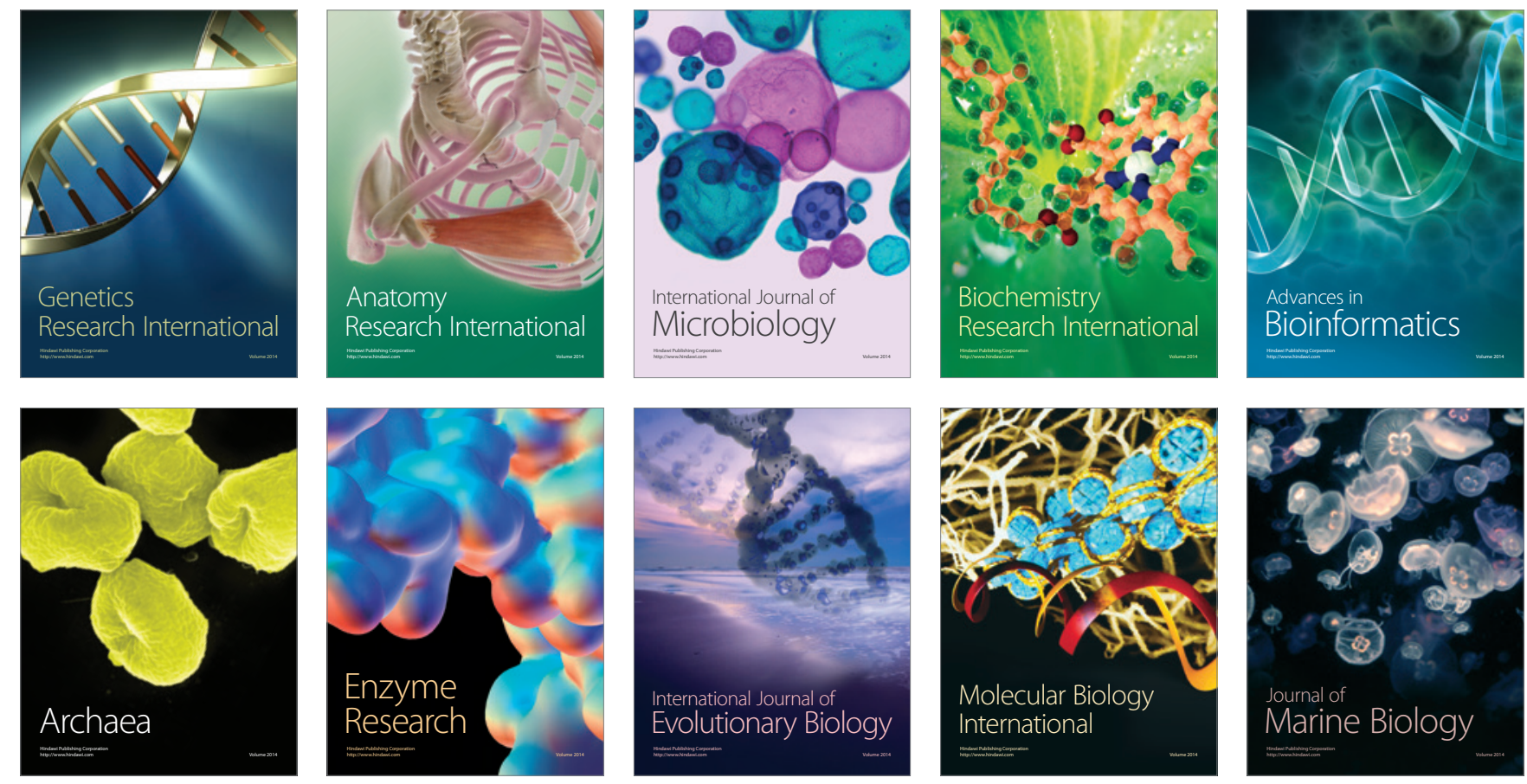